\title{
Assessment of Psychological Well-Being among Adolescent after Terrorist Attack
}

\author{
Mohanned A. Essa, $\mathrm{RN}^{1}$; Hassan A. Hussein, $\mathrm{PhD}^{2}$ \\ ${ }^{I}$ (Technical Trainer, technical Medical Institute in Baghdad, Iraq) \\ ${ }^{2}$ (Instructor, Psychiatric Mental Health Nursing, College of Nursing, University of Baghdad, Iraq)
}

\begin{abstract}
Objectives: The study aims to identify the terror-related traumatic experience among students; to assessing the mental health of students; to find out the impact of terrorist trauma on mental health; and to examine the relationship between specific characteristics of students with mental health implication.

Methodology: A descriptive analytical study conducted through the period of the 8th of January, 2017 to 5 th of March, 2017. The study conducted on the students of the secondary schools in Rusafa and Karkh sectors of Baghdad city. The purposive sample of 246 male and female students was selected from the six scholastic stages (intermediate and preparatory stage). The Students Perceived questionnaire consisted of Part one: contains information about demographic characteristics of student. Part two: includes information about the Experience of the Terrorism Attack that the student experienced or witnessed. Part three: contains 38 question, The Mental Health Inventory (MHI-38) describes how student thinks during the past month were adopted and modified for achieve the objectives of the study; the data have been collected through the utilization of the self-administrative report as a mean of data collection. Data were analyzed through the application of descriptive and inferential statistical methods by using statistical package for social science (SPSS) version 20.0.

Results: The results show that students are significantly experiencing a traumatic event from terrorist attacks. $79.6 \%$ of the students are exposed to terrorist attack after it happened, More than half of them are exposed for the period of > year $(66.5 \%)$ which was high significant for them $(M . S=1.76)$.The results shows the students' mental health according to the global scales of psychological well-being and distress; it has been reported a fair level of psychological well-being by the students (80.1\%), and (72.3\%) of them are reveals a psychological distress..The results indicates that there is high significant relationship between students' mental health to their family income ( $p$-value $=0.002$ ).

Conclusions: The study concluded the students have terror-related traumatic experience. The majority of students are exposed to terrorist attack after it happened. More than half of them are exposed for the period of $>$ year which was high significant for them. More of the students are showing a fair status of mental health according to the total scale of Mental Health Index (MHI).So the study indicate impact of terrorist attack on students' mental health.

Recommendations: The study recommended working on the opening of psychological guidance and guidance centers in all secondary schools in Baghdad to detect and follow up the psychological state of students who have experienced the traumatic experience of terrorism, either directly or indirectly to ensure that their psychological condition does not worsen after the terrorist shock.
\end{abstract}

Keywords: Psychological Well-being, Terrorism

\section{Introduction}

Ancient societies did not define the crime of terrorism is common sense in the modern era, and in spite of it We find that this crime has extended through the roots of human history ${ }^{(1)}$.

There is no an international community consensus on a specific and clear definition of terrorism, and this is due no doubt to the worker Political and ideological, featured multiple definitions identified terrorism from a global perspective, and despite the contrast it, it refers to the acts of terrorism that threaten the political and social stability through the use of violence on the face is Project for gains and objectives drawn ${ }^{(2)}$.

While the United Nations defines terrorism, "as a crime against the peace and security of mankind as a whole. " (1). People are not born terrorists do not wake up one morning and decide to start planting bombs in public streets, the perception is important here is that terrorism is a process and "terrorism is an option suddenly; it's a political choice from a wide range of options" strategy ${ }^{(3)}$.

Iraq has seen repeated deadly attacks that have claimed many civilian casualties, disrupting daily life and the economy, and creates an atmosphere of fear and insecurity. Since 2003, 36900-54900 people have been killed and wounded in more terrorist attack ${ }^{(4)}$. The traumatic event or situation creates psychological trauma when controls on individuals perceived ability to cope, and leaves that person in fear of death, and the yard, distortion, or psychosis. Individual feels emotionally, cognitively, and physically overwhelmed. ${ }^{(5)}$.

DOI: 10.9790/1959-0603043742 $\quad$ www.iosrjournals.org $37 \mid$ Page


When terrorist attacks occur, and children may see or learn about these events by watching television, and talking with people at school, or hear adults discuss the events. For example, it received September 11, 2001 attacks and the bombing of Oklahoma City on a wide range of interest and media coverage and exposure of many children. ${ }^{(6)}$. Other studies have reported that the estimated $5 \%-11 \%$ of children and adolescents suffer from post-traumatic stress disorder in the wake of indirect exposure to such events of 9/11 and the Oklahoma City bombing $^{(7)} ;^{(8)}$.

However, all of the children and adolescents who have been exposed to incidents of terrorism through the media on the degree of emotional distress after indirect exposure showed. The studies conducted after the attack on the twin towers of the World Trade Center at a high level of distress among people who do not reside in New York ${ }^{(9)}{ }^{(10)}$.Can be diagnosed children and adolescents with PTSD if they are under natural and human life - presented disasters such as floods and violent crimes such as kidnapping, rape or murder of a parent, fire, school shootings, car accidents, and exposure to violence of society, war, sexual assault and physical ${ }^{(11)}$.

Adults can continue to help children work through their emotions, and maybe even use the process as a learning experience. some of these process( Model calm and control Children , Reassure the children, they are safe and (if true) and so are important to adults and other loved ones in their lives, Let the kids know it is okay to feel upset, Tell the children the truth. Do not try to pretend the event did not happen or that it is not serious, Control or limit exposure to scenes of the event as well as after. In particular, exposure monitoring social media, Keep the lines of communication open between home and school, Control your stress level. Do not ignore your feelings of anxiety, sadness, and anger. ${ }^{(12)}$.

\section{Objectives of the Study}

The purposes of this study:

1. To identify the terror- related traumatic experience among students.

2. To assessing the Psychological well-being of students.

3. To examine the relationship between specific characteristics of students with Psychological well-being implication.

\section{Methodology}

A descriptive analytic study carried on the 8th of January, 2017 to 5 th of March, 2017. An assessment approach is applied in order to achieve the earlier stated objectives for the present study. The current study has been conducted on the students of the secondary schools in Rusafa and Karkh sectors of Baghdad city. The sample of the study 246 male and female students was selected from the six scholastic stages. The sample was selected purposively (non- probability sampling). In order meet the students formally, the permission has been granted from the educational directorate of second Rusafa, educational directorate of first Karkh, These consents facilitated the researcher's entry to the selected schools and take the secondary permission from the administrators of schools and the student who participate in this study and their teachers.

The instrument of the study was adopted and modified by the researcher. The modifications were employed after considering the congestion of peer experts for more clear and adequate copy of the instrument to be appropriate for this study. The instrument consisted of three parts: Part one: contains information about demographic characteristics of student which include (Age, Gender, Scholastic stage, Family monthly income and "Have you lost any of your family members is a terrorist attack". Part two: This part includes information about the Experience of the Terrorism Attack that the student experienced or witnessed, and this part include following items: (Part I) To evaluate the researchers for these terrorism attacks and their responses, Part (II) Assessment the threating level in public, Part (III) Investigate about the experiences of invisible threats or their suffering during the attack. Part three: this part contains 38 question, The Mental Health Inventory (MHI-38) describes how student thinks during the past month the student after read each question must be tick the box by the ONE statement that best answers.

The data have been collected through the utilization of the self-administrative report as a mean of data collection. The questionnaire was distributed for the students after being willing to answer the questionnaire and participate in the study. Filling the questionnaire takes approximately $15-20$ minutes.

Statistical analyses were conducted by using statistical package for social science (SPSS) version 20.0. Data were analyzed through the application of descriptive and inferential statistical approaches which were performed through the computation of the following: frequencies, percentages, mean of score, standard deviation and chi-square. 


\section{Results}

Table 1: Distribution of the Students According to their Socio-demographic Characteristics

\begin{tabular}{|c|c|c|c|c|}
\hline No. & \multicolumn{2}{|l|}{ Characteristics } & f & $\%$ \\
\hline \multirow[t]{3}{*}{1} & \multirow[t]{3}{*}{ Age group: } & $12-16$ years & 143 & 58.1 \\
\hline & & $17-21$ years & 103 & 41.9 \\
\hline & & Total & 246 & 100 \\
\hline \multirow[t]{3}{*}{2} & \multirow[t]{3}{*}{ Gender: } & Male & 123 & 50 \\
\hline & & Female & 123 & 50 \\
\hline & & Total & 246 & 100 \\
\hline \multirow[t]{3}{*}{3} & \multirow[t]{3}{*}{ Scholastic stage: } & Intermediate & 123 & 50 \\
\hline & & preparatory & 123 & 50 \\
\hline & & Total & 246 & 100 \\
\hline \multirow[t]{4}{*}{4} & \multirow[t]{4}{*}{ Family income: } & Insufficient & 45 & 18.4 \\
\hline & & Barely sufficient & 102 & 41.2 \\
\hline & & Sufficient & 99 & 40.4 \\
\hline & & Total & 246 & 100 \\
\hline \multirow[t]{5}{*}{5} & \multirow[t]{5}{*}{ Lost of family member: } & None & 220 & 89.4 \\
\hline & & Father & 12 & 4.9 \\
\hline & & Mother & 2 & 0.8 \\
\hline & & Brother & 12 & 4.9 \\
\hline & & Total & 246 & 100 \\
\hline
\end{tabular}

No: Number, f: Frequency, \%: Percentage

The table (1) shows the descriptive analysis of the sample which is reveals that more than half of the students are in age group of $12-27$ years old (58.1\%). Regarding gender variable, the students were equally selected from both genders (Male: Female, 50\%). The scholastic stage was also equally selected from both stages; intermediate and preparatory $(50 \%)$.Close percentages were seen related to family income that found $41.2 \%$ of the students associated with barely sufficient income. $89.4 \%$ of the students showing that they didn't loss of their family member due to terrorist attack.

Table 2: Students' Traumatic Experience Related to Terrorist Attack

\begin{tabular}{|c|c|c|c|c|c|c|}
\hline \multicolumn{3}{|c|}{ Experience's Variables } & f & $\%$ & M.S & Sig. \\
\hline \multirow{3}{*}{ 产 } & \multirow{3}{*}{$\begin{array}{l}\text { Exposure to terrorist } \\
\text { attack: }\end{array}$} & During attack & 50 & 20.4 & \multirow{3}{*}{1.80} & \multirow{3}{*}{$\mathrm{S}^{*}$} \\
\hline & & After attack & 196 & 79.6 & & \\
\hline & & Total & 246 & 100 & & \\
\hline. & \multirow[t]{5}{*}{ Type of terrorist attack: } & Explosion & 209 & 84.9 & \multirow{5}{*}{1.23} & \multirow{5}{*}{ N.S ${ }^{* *}$} \\
\hline$\ddot{b}$ & & Murder & 25 & 10.2 & & \\
\hline 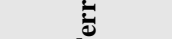 & & Kidnapping & 5 & 2 & & \\
\hline E & & Other & 7 & 2.9 & & \\
\hline \multirow{4}{*}{ 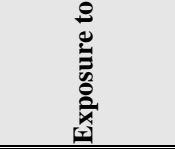 } & & Total & 246 & 100 & & \\
\hline & \multirow[t]{3}{*}{ Period of exposure: } & $<$ year & 82 & 33.5 & \multirow{3}{*}{1.76} & \multirow{3}{*}{ H.S ${ }^{*}$} \\
\hline & & $>$ year & 164 & 66.5 & & \\
\hline & & Total & 246 & 100 & & \\
\hline \multirow{13}{*}{ 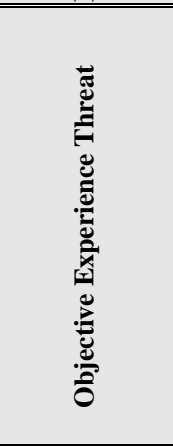 } & \multirow[t]{3}{*}{ See corpses \& dead bodies: } & Yes & 207 & 84.1 & \multirow{3}{*}{0.84} & \multirow{3}{*}{ H.S S $^{* * * *}$} \\
\hline & & No & 39 & 15.9 & & \\
\hline & & Total & 246 & 100 & & \\
\hline & \multirow{3}{*}{$\begin{array}{l}\text { Heard from Witnessed } \\
\text { people: }\end{array}$} & Yes & 195 & 79.2 & \multirow{3}{*}{0.79} & \multirow{3}{*}{ H.S S $^{* * * *}$} \\
\hline & & No & 51 & 20.8 & & \\
\hline & & Total & 246 & 100 & & \\
\hline & \multirow{3}{*}{$\begin{array}{l}\text { Heard Shout \& scream of } \\
\text { victims: }\end{array}$} & Yes & 96 & 39.1 & \multirow{3}{*}{0.39} & \multirow{3}{*}{$\mathrm{S}^{* * *}$} \\
\hline & & No & 150 & 60.9 & & \\
\hline & & Total & 246 & 100 & & \\
\hline & \multirow[t]{4}{*}{ Psychological distress: } & Mild & 117 & 47.3 & \multirow{4}{*}{1.66} & \multirow{4}{*}{ N.S S $^{* * * * *}$} \\
\hline & & Moderate & 97 & 39.6 & & \\
\hline & & Severe & 32 & 13.1 & & \\
\hline & & Total & 246 & 100 & & \\
\hline \multirow{4}{*}{ 冚 } & \multirow[t]{4}{*}{ Subjective experience: } & Mild & 31 & 12.7 & \multirow{4}{*}{2.27} & \multirow{4}{*}{$\mathrm{S}^{* * * * *}$} \\
\hline & & Moderate & 118 & 48.2 & & \\
\hline & & Severe & 96 & 39.2 & & \\
\hline & & Total & 240 & 100 & & \\
\hline
\end{tabular}

f: Frequency, \%: Percentage, M.S: Mean of score, Sig.: Significant, H.S: Highly significant, S:

Significant, N.S: Not Significant

* Significant score (N.S = 1 - 1.33, S = 1.34 - 1.67, H.S = 1.68 - 2)

${ }^{* *}$ Significant score $(\mathrm{N} . \mathrm{S}=1-2, \mathrm{~S}=2.1-3, \mathrm{H} . \mathrm{S}=3.1-4)$

${ }^{* * * *}$ Significant score $($ N.S $=0-0.33, S=0.34-0.67$, H.S $=0.68-1)$

${ }^{* * * * *}$ Significant score $($ N.S $=1-1.66, S=1.67-2.33$, H.S $=2.34-3$ ) 
The overview of table reveals that students are significantly experiencing a traumatic event from terrorism works. $79.6 \%$ of the students are exposed to terrorist attack after it happened. More than half of them are exposed for the period of > year $(66.5 \%)$ which was high significant for them $(\mathrm{M} . \mathrm{S}=1.76)$. The analysis of objective threats shows that $84.1 \%$ of them are seeing corpses and dead bodies, $79.2 \%$ of them are hearing from witnessed people, while only $39.1 \%$ of them hearing shout and screaming of the victims. The psychological distress associated with objective threats was not significant for the students $(M . S=1.66)$, in which the highest percentage showing a mild psychological distress (47.3\%) while remaining showing a moderate $(39.6 \%)$ to severe $(13.1 \%)$ distress. The analysis of subjective threats reveals a significant among students (M.S $=2.27)$ that they experiencing a moderate subjective threat of traumatic event $(48.2 \%)$.

Table 3: Students' Mental Health According to the Total Mental Health Index (MHI)

\begin{tabular}{|l|c|c|c|c|}
\hline Levels of MHI & f & \% & M.S & SD \\
\hline Poor & 27 & 11 & & \multirow{2}{*}{0.443} \\
\hline Fair & $\mathbf{1 9 8}$ & $\mathbf{8 0 . 4}$ & & \\
\cline { 1 - 3 } Good & 21 & 8.6 & & \\
\hline Total & $\mathbf{2 4 6}$ & $\mathbf{1 0 0}$ & & \\
\hline
\end{tabular}

f: Frequency, \%: Percentage, M.S: Mean of Score, SD: Standard Deviation Range of Score: $($ Poor $=38-63$, Fair $=64-89$, Good $=90-114)$

The table shows that more of the students are showing a fair status of mental health $(80.4 \%)$.

Table 4: Students' Mental Health According to their Psychological Wellbeing and Distress (N=246)

\begin{tabular}{|c|c|c|c|c|}
\hline Levels of Mental Health & f & $\%$ & M.S & SD \\
\hline Psychological Well-being & & & \multirow{4}{*}{1.93} & \multirow{4}{*}{0.443} \\
\hline Poor & 33 & 13.4 & & \\
\hline Fair & 187 & 80.1 & & \\
\hline Good & 16 & 6.5 & & \\
\hline \multicolumn{3}{|l|}{ Psychological Distress: } & \multirow{4}{*}{1.96} & \multirow{4}{*}{0.825} \\
\hline Mild & 39 & 15.8 & & \\
\hline Moderate & 178 & 72.3 & & \\
\hline Severe & 29 & 11.9 & & \\
\hline
\end{tabular}

f: Frequency, \%: Percentage, M.S: Mean of Score, SD: Standard Deviation

Range of Score: Well-being (Poor $=14-23$, Fair $=24-33$, Good $=34-42)$

Distress $($ Mild $=24-40$, Moderate $=41-57$, Severe $=58-72)$

This table presents the students' mental health according to the global scales of psychological well-being and distress; it has been reported a fair level of psychological well-being by the students (80.1\%), and $72.3 \%$ of them are reveals a psychological distress.

Table 5: The Association of Psychological Well-being of students with their Clinical and Demographic Variables

\begin{tabular}{|l|c|c|c|c|}
\hline Students' Variable & Chi-square & d.f & P-Value $\leq \mathbf{0 . 0 5}$ & Significance \\
\hline Age & 3.621 & 2 & 0.164 & N.S \\
\hline Gender & 1.375 & 2 & 0.503 & N.S \\
\hline Income & 16.485 & 4 & 0.002 & S \\
\hline Scholastic stage & 1.375 & 2 & 0.503 & N.S \\
\hline Period of Exposure & 1.700 & 2 & 0.427 & N.S \\
\hline Lost of family member & 5.179 & 4 & 0.521 & . \\
\hline
\end{tabular}

\section{d.f: Degree of freedom, P-Value: Probability value, N.S: Not Significant, S: Significant}

These findings indicate there is no significant relationship between students' Psychological Well-being and their clinical and demographic variables except family income, which is significant associated with Psychological Well-being $(\mathrm{p}$-value $=0.002)$ at $\mathrm{p}$-value $\leq 0.05$.

\section{Discussion}

According to the descriptive analysis of findings the table (1) show sample which is reveals that more than half of the students are in age group of $12-27$ years old $(58.1 \%)$. Regarding gender variable, the students were equally selected from both genders (Male: Female, 50\%).close percentages were seen related to family income that found $(41.2 \%)$ of the students associated with barely sufficient income. The researchers' opinion for this result due to the nature economic status for the citizen in the Baghdad city .

The study shows in Table (2) that the traumatic experience related to terrorist attack; the overview of table reveals that students are significantly experiencing a traumatic event from terrorism acts. $79.6 \%$ of the students are exposed to terrorist attack after it happened. According to result more than half of them are 
exposed for the period of $>$ year $(66.5 \%)$ which was high significant for them (M.S= 1.76). These results are consistent with Hijazi ${ }^{(13)}$. found that children and adolescents traumatic events was watching the shelling and funerals by $(90.3 \%)$ while the lowest percentage of watching their families were injured or killed by $(4.28 \%)$ This means that the children's experience of indirect traumatic experience is relatively large in view of what they see and hear through the daily events of watching the shelling and demolition of homes and funerals, shooting and watching the wounded and martyrs on a daily basis. Also consistent with Adams et al ${ }^{(14)}$ Found the exposure to terrorism violence through the media, videogames, movies, or news about disasters and/or individual incidents has different implications for the pediatric population, and multiple studies have shown a link to adverse mental health effects in children. The researchers explain this as result of the most students usually stayed more time in the school or home therefore they watching terrorist attack from different media methods after they happened.

The study shows in Table (3) more of the students are showing a fair status of mental health $(80.4 \%)$. According to the total scale of Mental Health Index (MHI) It is clear to the researchers through the above result that the existence of a normal childhood in Iraq is unlikely in the current circumstances, and that the future of the child's psychological in future will be at risk of being subjected to traumatic and continuous terrorist experience.

Table (4) the study indicated students' mental health according to the global scales of psychological well-being and distress; it has been reported a fair level of Psychological well-being by the students (80.1\%), and (72.3\%) of them are reveals a psychological distress. These results consistent with Moscardino and other ${ }^{(15)}$ who concluded more than a year after a terrorist attack, adolescents may face psychological distress regardless of whether they are directly or indirectly exposed.

Table (5) show that students with age of $12-16$ years old are showing a fair level of mental health; that there is no significant relationship between Psychological well-being and students' age group at $\mathrm{p}$-value $\leq 0.05$. This result is contrast with study by Jose et al ${ }^{(16)}$. Who Found age, race or ethnicity; do not show a consistent relationship with major depressive disorder.

Results show that male students having fair level of mental health more than female students that there is no significant relationship between students' gender with their Psychological well-being at $\mathrm{p}$-value $\leq 0.05$. This current result of the study is inconsistent with study by Jose et al ${ }^{(16)}$. Who found a gender relationship and the risk of major depressive disorder following terrorist attacks, with women continuing to become increasingly vulnerable to mine detection after these events?

This result has been documented in direct victims of terrorist attacks and in the general population. Results shows that fair level of mental health is associated with barely sufficient students; the table indicates that there is high significant relationship between students' Psychological well-being with respect to their family income ( $\mathrm{p}$-value $=0.002)$. These result consistent with Fergusson et al ${ }^{(17)}$ The study found poverty also seems to have cumulative effects. Chronic exposure to poverty increases the risk of adolescents due to mental disorders such as depression and behavioral risks. Also the study results shows that students at intermediate stage showing mental health more than secondary stage which they have a fair level of mental health; the table indicates that there is no significant relationship between Psychological well-being and scholastic stage at $p$-value $\leq 0.05$.In view of point of the researcher the positive traits of personality can reduce the effects of terrorist attack. Also the researcher opinion for this result this may be due to (parents, teachers, older friends and others social support) introduce for students. Results show there is no significant relationship between students' Psychological wellbeing with their period of exposure to the terrorist attack at $p$-value $\leq 0.05$. This result is inconsistent with study by Famularo and other ${ }^{(18)}$ who suggest that Individuals with chronic trauma have lower recovery rates than PTSD The researchers explain this as result of they have more adaptive within these experience and the most of the sample were indirectly exposed to terrorist attack. The current study results show that there is no significant relationship between loss of member and mental health among adolescents at $p$-value $\leq 0.05$. The researchers attributed the reason for the lack of a relationship of statistical significance is that most of the respondents did not lose a family member.

\section{Conclusion}

(1)The majority of students are exposed to terrorist attack after it happened. More than half of them are exposed for the period of $>$ year which was high significant for them.

(2) The study results indicate the impact of terrorist attack on students' mental health.

(3) The study indicates that more of the students are showing a fair status of mental health according to the total scale of Mental Health Index (MHI).Also shows a fair level of psychological well-being by the students $(80.1 \%)$, and $(72.3 \%)$ of them are reveals a psychological distress. 


\section{Recommendation}

(1)Working on the opening of psychological guidance and guidance centers in all secondary schools in Baghdad to detect and follow up the psychological state of students who have experienced the traumatic experience of terrorism, either directly or indirectly to ensure that their psychological condition does not worsen after the terrorist shock.

(2) To appeal to the government to avoid showing scenes of terrorism practiced by extremist religious groups and to refer those directly exposed to terrorist trauma to post-trauma psychological rehabilitation centers.

\section{References}

[1] AbdelMuttalib, M., Definition of international terrorism between political considerations and objective considerations, New University House, Alexandria, Egypt, 2007

[2] Ghaith, M., Dictionary of Social Sciences, Social Knowledge House, Alexandria, Egypt 1989.

[3] Silke, A. P., Cheshire-cat logic: The recurring theme of terrorist abnormality in psychological research. Psychology, Crime and Law (1998). 4:51-69.

[4] United Nations Iraq (UN Iraq), 2017

[5] Giller, E., About trauma, what is psychological trauma? The sidran institute. (http://www.sidran.org) 2003.

[6] Schuster, M.A., Stein, B.D., Jaycox, L.H., Collins, R.L., Marshall, G.N., Elliott, M.N., Zhou, A.J., Kanouse, D.E., Morrison, J.L. \& Berry, S.H ., A national survey of stress reactions after the September 11, 2001.

[7] Hoven, C. W \& Duarte, C. S. 1., Effects of the World Trade Center Attack on NYC Public School Students - Initia 1 Report of the New York Board of Education (pp. 1-40). New York, Applied Research and Consulting, LLC Columbia University Mailman School of Public Health New York State Psychiatric Institute . 2002.

[8] Pfefferbaum B, Sconzo GM., Case findings and mental health services for children in the aftermath of the Oklahoma City bombing. The Journal of Behavioral Health Services and Research, 2003, 30 (2) , 215- 227

[9] Cohen- Silver, R. C., Holman, E. A., McIntosh, D. N., Poulin, M., \& Gil-Rivas, V. Nationwide longitudinal study of psychological responses to September 11 . Journal of the American Medical Association Conflicts and Terrorism, University of Turku, Finland, The Eurasian Politician, 19th July2002, 288, 1235-1244.

[10] Schlenger, W.E., Caddell, J. M., Ebert, L., Jordan, B. K., Rourke, K. M., Wilson, D., Thalji, L., Dennis, J. M., Fairbank, J. A \& Kul ka, R. A Psychological Reactions to Terrorist Attacks: Find ings from the National Study of Americans' Reactions to September 11. The Journal of the American Association, 2002. 288, 581-588.

[11] Hamblen, J. \& Schnurr, P., Mental Health aspects of prolonged combat stress in Civilians. National center for PTSD fact sheet. 2003.

[12] National Association of School Psychologists, 4340 East West Highway, Suite 402, Bethesda, 2015 MD 20814, (301) 657-0270, Fax (301) 657-0275.

[13] Hijazi, H., Traumatic experience and its relationship to the symptoms of disorders and some personality traits of the children of the martyrs of the Al Aqsa Intifada 2004

[14] Adams RE, Laraque D, Chemtob CM, Jensen PS \&Boscarino JA ., Does a one-day educational training session influence primary care pediatricians' mental health practice procedures in response to a community disaster? Results from the reaching children initiative (RCI) . International Journal Emergency Mental Health 2013, 15(1):3-14.

[15] Moscardino U, Scrimin S, Capello F, Altoè G \& Axia G ., Psychological adjustment of adolescents 18 months after the terrorist attack in Beslan, Russia: a cross-sectional study2008.

[16] José M Salguero., Pablo Fernández-Berrocal .,Itziar Iruarrizaga .,Antonio Cano-Vindel \& Sandro Galea., Major depressive disorder following terrorist attacks: A systematic review of prevalence, course and correlates. Biomed central psychiatry v. 11; 2011

[17] Fergusson, D. M., Woodward, L. J., \& Horwood, L. J., Risk factors and life processes associated with the onset of suicidal behaviour during adolescence and early adulthood. Psychological Medicine, 2000. 30, 23-39.

[18] Famularo R1., Fenton T., Kinscherff R ., Augustyn M., Psychiatric comorbidity in childhood post-traumatic stress disorder. Child Abuse \&Neglect. 1996 Oct; 20(10):953-61. 